\title{
Biokinetics of zinc oxide nanoparticles: toxicokinetics, biological fates, and protein interaction
}

This article was published in the following Dove Press journal:

International Journal of Nanomedicine

15 December 2014

Number of times this article has been viewed

\section{Soo-Jin Choi' \\ Jin-Ho Choy ${ }^{2}$}

'Department of Food Science and Technology, Seoul Women's University, ${ }^{2}$ Center for Intelligent Nano Bio Materials (CINBM), Department of Bioinspired Science and Department of Chemistry and Nanoscience, Ewha Womans University, Seoul, South Korea
Correspondence: Soo-Jin Choi

Department of Food Science and Technology, Seoul Women's University

62I Hwarang-ro, Nowon-gu,

Seoul 139-774, South Korea

Tel +82 29705634

Fax +82 29705977

Email sjchoi@swu.ac.kr

Jin-Ho Choy

II-I Daehyun-dong, Seodaemun-gu,

Seoul 120-750, South Korea

$\mathrm{Tel}+82232774135$

Fax +82232774340

Email jhchoy@ewha.ac.kr
Abstract: Biokinetic studies of zinc oxide $(\mathrm{ZnO})$ nanoparticles involve systematic and quantitative analyses of absorption, distribution, metabolism, and excretion in plasma and tissues of whole animals after exposure. A full understanding of the biokinetics provides basic information about nanoparticle entry into systemic circulation, target organs of accumulation and toxicity, and elimination time, which is important for predicting the long-term toxic potential of nanoparticles. Biokinetic behaviors can be dependent on physicochemical properties, dissolution property in biological fluids, and nanoparticle-protein interaction. Moreover, the determination of biological fates of $\mathrm{ZnO}$ nanoparticles in the systemic circulation and tissues is critical in interpreting biokinetic behaviors and predicting toxicity potential as well as mechanism. This review focuses on physicochemical factors affecting the biokinetics of $\mathrm{ZnO}$ nanoparticles, in concert with understanding bioavailable fates and their interaction with proteins.

Keywords: $\mathrm{ZnO}$ nanoparticles, biokinetics, distribution, excretion, fate, interaction

\section{Introduction}

Zinc oxide $(\mathrm{ZnO})$ nanoparticles represent an important class of commercially applied materials. They have been widely applied in diagnostics, therapeutics, drug-delivery systems, electronics, cosmetics, personal care products, and food additives, due to their magnetic, catalytic, semiconducting, antimicrobial, ultraviolet-protective, and binding properties. ${ }^{1-4}$ However, the increasing use of $\mathrm{ZnO}$ nanoparticles has raised concern about their potential toxicity for humans and the environment. The majority of in vivo toxicity studies on $\mathrm{ZnO}$ nanoparticles have investigated acute toxicity and subacute toxicity after a single or repeated dosing, respectively, via inhalation, ingestion, injection, or dermal penetration. ${ }^{5-10}$ However, much work has yet to been done to determine absorption amounts and bioavailability. Pharmacokinetic (PK) studies require a systematic and thorough quantitative analysis of absorption, distribution, metabolism, and excretion in whole animals, and provide measures of kinetic profiles in plasma and all tissues until the agent is completely cleared from the body. ${ }^{11,12}$ Thus, PK studies provide basic information about nanoparticle entry into systemic circulation, organs targeted for accumulation, and time required for elimination. Kinetic parameters provide information on the half-lives and residence times of nanoparticles, and thus PK studies are needed to understand the biological interactions of nanoparticles with tissues and to determine the effects of long-term exposure. On the other hand, toxicokinetics (TK) applies PK tools to define the relationship between kinetic behaviors of a toxicant and the occurrence of toxic events. ${ }^{13}$ Both PK and TK profiles of nanoparticles are highly dependent on exposure routes and physicochemical properties, 
such as size, shape, surface charge, surface chemistry, and chemical composition. ${ }^{11,14}$

Unlike other metal oxide nanoparticles, such as titanium dioxide, cerium oxide, and iron oxide, $\mathrm{ZnO}$ nanoparticles are not highly stable and tend to dissolve in aqueous solutions, subsequently releasing zinc ions from the particles. ${ }^{15-18}$ The solubility of $\mathrm{ZnO}$ nanoparticles depends on $\mathrm{pH}$, concentration, particle size, and the presence of organic compounds. ${ }^{15,19,20}$ Thus, their instability and solubility under physiological conditions pose a challenge in distinguishing if the toxicity of $\mathrm{ZnO}$ nanoparticles results from the particulate or zinc toxicity. Controversies continue to exist on the toxicity of $\mathrm{ZnO}$ nanoparticles as well as their fates in biological systems. ${ }^{21-23}$ This review summarizes the biokinetic behaviors of $\mathrm{ZnO}$ nanoparticles obtained by different approaches, with discussion of TK, target organs, solubility, biological fates, and toxicity potentials.

\section{Biokinetic behaviors Absorption}

Time-course analysis of plasma concentrations after administering a single dose of $\mathrm{ZnO}$ nanoparticles is an effective method for quantification of absorption and bioavailability, and helps in the estimation of distribution as well as elimination phases. ${ }^{24}$ Most absorption studies on $\mathrm{ZnO}$ nanoparticles evaluate biokinetics after a single- or repeated-dose oral exposure, since oral administration generally decreases bioavailability due to gastrointestinal barriers, the firstpass effect, and incomplete absorption related to liver and gut-wall functions. On the other hand, intravenously injected nanomaterials directly enter the systemic circulation, and thus in principle obtain $100 \%$ bioavailability. Determining biokinetic properties of $\mathrm{ZnO}$ nanoparticles often relies on the quantitative analytical techniques commonly applied to inorganic materials, ie, quantification of zinc content in biological samples. Methods for quantification include inductively coupled plasma-atomic emission spectroscopy, inductively coupled plasma-mass spectroscopy, and atomic absorption spectrophotometry.

Following a single oral administration, plasma concentration versus time profiles of $\mathrm{ZnO}$ nanoparticles are highly dependent on exposure dose. When three different doses $(50,300$, and $2,000 \mathrm{mg} / \mathrm{kg})$ of two different nanoparticle diameters (20 and $70 \mathrm{~nm})$, dispersed in citrate/4-(2hydroxyethyl)-1-piperazineethanesulfonic acid (HEPES), were orally administered to rats, all PK parameters, such as, maximum concentration, time to reach maximum concentration $\left(\mathrm{T}_{\max }\right)$, area under the plasma concentration-time curve (AUC; a measure of the total amount that reaches the systemic circulation), half-life $\left(\mathrm{t}_{1 / 2}\right)$, and mean residence time (average time that a molecule remains in the body), increased clearly in a dose-dependent manner. ${ }^{25}$ In particular, the absorption rate and distribution phase were highly dependent on exposure dose, showing $\mathrm{T}_{\max }$ values at 1,6 , and 24 hours after receiving 50,300, and 2,000 mg/kg, but returned to normal levels within 6, 24, and 96 hours, respectively (Figure 1). Oral absorption efficiency was determined to be about $13 \%, 25 \%$, and $31 \%$, respectively. Interestingly,

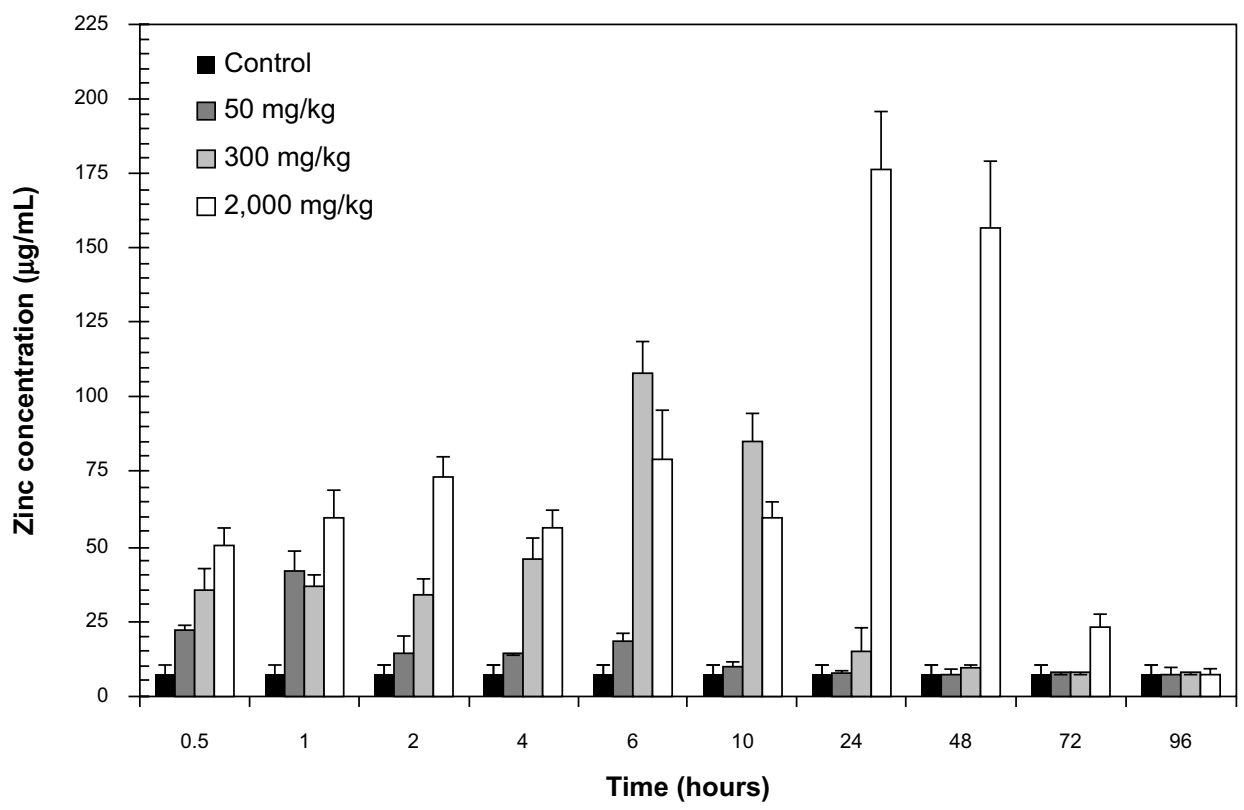

Figure I Plasma concentration-time curves of $20 \mathrm{~nm}$ zinc oxide $(\mathrm{ZnO})$ nanoparticles after a single oral administration to male rats. 
no significant differences between particle sizes or sex were demonstrated.

Further kinetic behavior studies on surface-charge effects (negative and positive) of $\mathrm{ZnO}$ nanoparticles showed that negatively charged particles (capped with citrate/HEPES, $\mathrm{ZnO}^{-}$) were absorbed in larger amounts than positively charged particles (capped with L-serine/HEPES, $\mathrm{ZnO}^{+}$), about $11 \%, 15 \%$, and $16 \%$ absorptions for 50,300 , and $2,000 \mathrm{mg} / \mathrm{kg}$ doses, respectively. ${ }^{26}$ Therefore, it was concluded that surface charge rather than particle size was the dominating factor affecting absorption efficiency. Mechanistic studies are further needed to understand the reason for the high absorption efficiency of negatively charged $\mathrm{ZnO}$ nanoparticles compared to positively charged particles. On the basis of absorption efficiency, $\mathrm{ZnO}$ nanoparticles with negative charge can be more efficient for biological application, whereas positively charged particles may cause less toxicity. Table 1 summarizes the particle size, surface charge, and pharmacokinetic behaviors of $\mathrm{ZnO}$ nanoparticles. Moreover, kinetic behaviors of $\mathrm{ZnO}$ nanoparticles in all cases differed from those of zinc ions compared to $\mathrm{ZnCl}_{2}$ administration, showing a rapid absorption rate, high absorption amount, and long $t_{1 / 2}$ for zinc ions. ${ }^{26}$ Therefore, the particulate form seems to be primarily absorbed into the bloodstream.

After repeated-dose administration, the TK of $\mathrm{ZnO}$ nanoparticles is different from that obtained by a single exposure. The absorption of $40 \mathrm{~nm} \mathrm{ZnO}$ nanoparticles dispersed in distilled water was investigated following repeated oral administration to rats by measuring blood zinc concentration after 13 weeks of the treatment; ${ }^{27}$ a clear dose-response relationship was demonstrated, showing significantly increased zinc levels in rats administered $536.8 \mathrm{mg} / \mathrm{kg}$ but not in rats treated with 134.2 and $268.4 \mathrm{mg} / \mathrm{kg}$. This suggests that the highest dose administered remained in the blood circulation 24 hours after final gavage. The no observed adverse-effect level of $\mathrm{ZnO}$ nanoparticles was $268.4 \mathrm{mg} / \mathrm{kg}$ for both male and female rats, ${ }^{27}$ which seems to be closely correlated to persistence at $536.8 \mathrm{mg} / \mathrm{kg}$ in the body. Similar observations were found in a repeated dose 90 -day oral TK study of $20 \mathrm{~nm} \mathrm{ZnO}$ nanoparticles suspended in citrate/HEPES in rats; ${ }^{28}$ a significant increase in plasma zinc levels was detected in rats administered $250 \mathrm{mg} / \mathrm{kg}$ at 90 days and $500 \mathrm{mg} / \mathrm{kg}$ at $28-90$ days. Furthermore, elevated plasma zinc levels were found in some rats treated with $125 \mathrm{mg} / \mathrm{kg}$. The difference in zinc-level persistence between the former and latter studies may have been due to different particle sizes tested or dispersing conditions. Nevertheless, repeated oral exposure of $\mathrm{ZnO}$ nanoparticles could lead to systemic

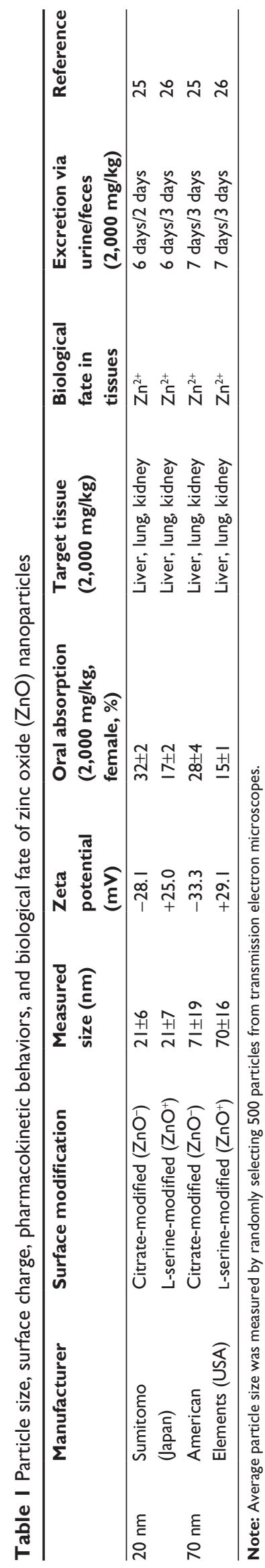


long-term accumulation, which may imply potential toxicity after long-term exposure. Worth noting is that the tolerable upper intake level for zinc is $40 \mathrm{mg}$ /day in adults. ${ }^{29}$ More caution needs to be taken when the human body is repeatedly exposed to nanoparticles.

Another important factor to be considered for understanding $\mathrm{TK}$ of $\mathrm{ZnO}$ nanoparticles is their fates in the bloodstream. The kinetics of neutron-activated ${ }^{65} \mathrm{ZnO}$ nanoparticles of two different sizes (10 and $71 \mathrm{~nm}$ ) was evaluated in mice after intravenous injection, with ${ }^{65} \mathrm{ZnNO}_{3}$ as a control; ${ }^{30}$ the kinetic parameters for the two nanoparticle sizes were similar, but greater plasma AUC and $\mathrm{t}_{1 / 2}$ values were found for ${ }^{65} \mathrm{ZnNO}_{3}$ than ${ }^{65} \mathrm{ZnO}$ nanoparticles. These results are in good agreement with the report by Paek et al, described earlier. ${ }^{26}$ Although part of the $\mathrm{ZnO}$ nanoparticles can dissolve in biological fluids, the kinetic behaviors of $\mathrm{ZnO}$ nanoparticles in terms of absorption are likely different from those of zinc ions. Therefore, the nanoparticles are likely to be primarily present in particulate forms in the systemic circulation.

\section{Distribution}

The tissue distribution of $\mathrm{ZnO}$ nanoparticles has been evaluated in whole animals, often associated with toxicity evaluation. Tissue-distribution study is essential in identifying target organs and target-specific toxicity, and requires quantification of nanoparticle distribution over various organ systems following a single or repeated exposure. Tissue-distribution kinetics after a single administration provides residence times of nanoparticles in the body and elimination times.

Tissue-distribution patterns are highly dependent on exposure route, animals, and the physicochemical properties of nanoparticles. Orally administered $\mathrm{ZnO}$ nanoparticles of 20 and $70 \mathrm{~nm}$ capped with citrate/HEPES or L-serine/HEPES were determined to accumulate in kidneys, liver, and lungs in rats after a single-dose administration, regardless of particle size, surface charge, or sex (Table 1 and Figure 2). ${ }^{25,26}$ Tissue-distribution kinetics demonstrated a similar tendency to that found in plasma concentration-time profile (Figure 1), showing elevated zinc concentrations at 6-24 hours and 1-2 days in kidneys and liver after administration of 300 and $2,000 \mathrm{mg} / \mathrm{kg}$, but returned to normal levels at 2 and 7 days, respectively. High retention of $\mathrm{ZnO}$ nanoparticles in lungs for the first hour can be explained by the fact that particles of $30-80 \mathrm{~nm}$ tend to be generally sequestered in lung tissue. ${ }^{31}$ The same target organs for $\mathrm{ZnO}$ nanoparticles were determined by applying optical imaging of Cy5.5-conjugation and positron emission tomography imaging of fluorinated particles. ${ }^{32,33}$ $\mathrm{ZnO}$ nanoparticles of $40 \mathrm{~nm}$ distributed to the liver and kidneys following repeated oral administration to rats for
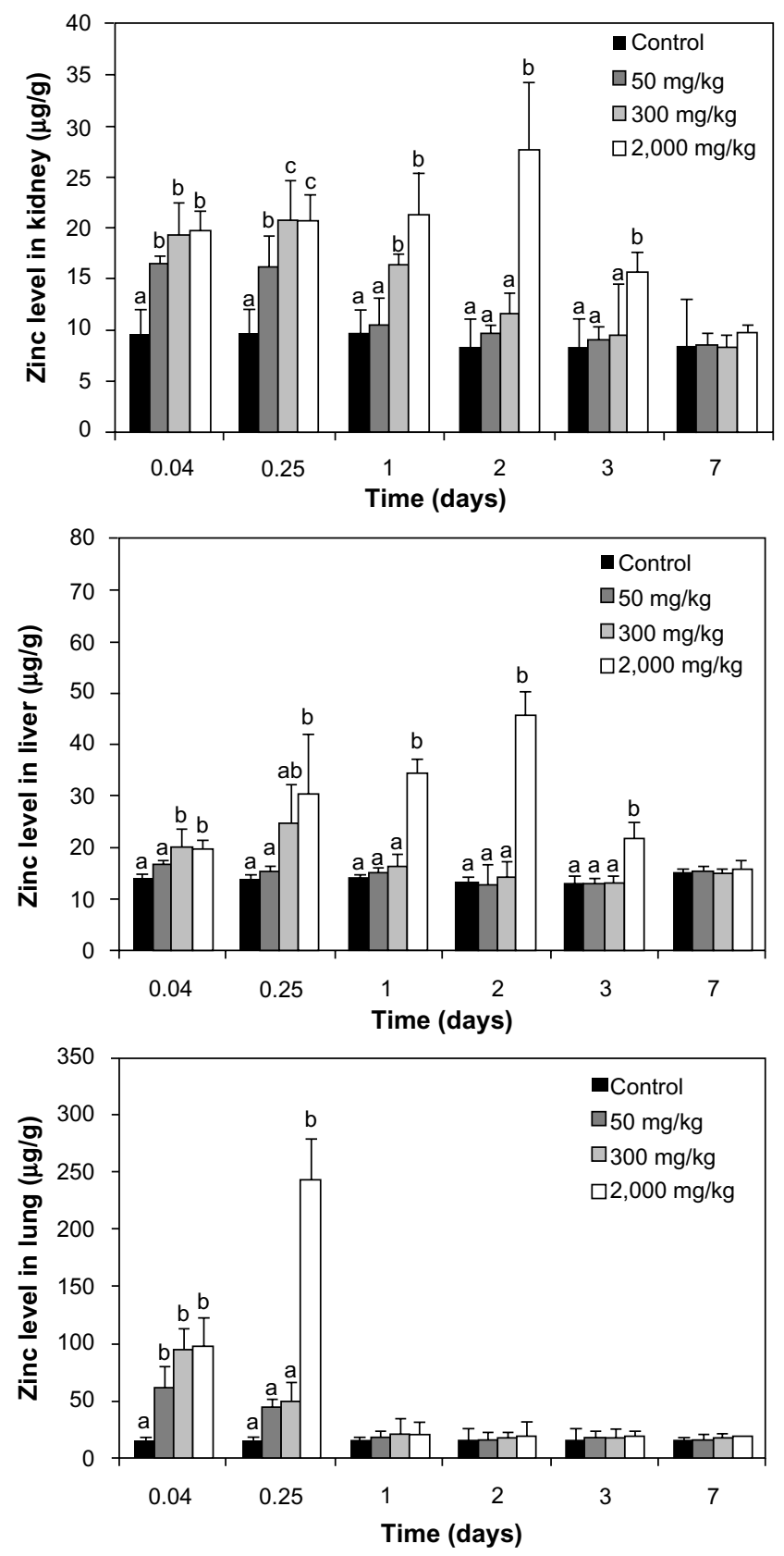

Figure 2 Tissue-distribution kinetics of $20 \mathrm{~nm}$ zinc oxide $(\mathrm{ZnO})$ nanoparticles after a single oral administration to male rats.

Note: There are statistically significant differences between columns labeled (a) and columns labeled $(b)(P<0.05)$.

13 weeks; however, lung distribution was not included in this study. ${ }^{21}$ On the other hand, elevated zinc levels were detected in the liver, spleen, and kidneys in mice orally administered $\mathrm{ZnO}$ nanoparticles of about $93 \mathrm{~nm}$, and caused acute liver toxicity. ${ }^{34}$ Different tissue-distribution patterns between oral $\mathrm{ZnO}$ nanoparticles and $\mathrm{ZnCl}_{2}$ were demonstrated, showing higher distribution of $\mathrm{ZnO}$ nanoparticles in lungs, but lower distribution in kidneys and liver than $\mathrm{ZnCl}_{2} \cdot{ }^{26}$ 
Gamma ray-emitting radioactive $\mathrm{ZnO}$ nanoparticles were primarily distributed in lungs and to a lesser extent in the liver, kidneys, and spleen after a single intravenous injection to mice ${ }^{35}$ The liver, spleen, kidneys, and lungs were found to be the main target organs for neutron-activated ${ }^{65} \mathrm{ZnO}$ nanoparticles of two different sizes (10 and $71 \mathrm{~nm}$ ) in mice following intravenous injection, showing a size-dependent effect; ${ }^{30}$ high tissue accumulation was found for $10 \mathrm{~nm}$ ${ }^{65} \mathrm{ZnO}$ versus $71 \mathrm{~nm}{ }^{65} \mathrm{ZnO}$ particles. On the other hand, the highest zinc-tissue levels were found in kidneys after injection of ${ }^{65} \mathrm{ZnNO}_{3}$, while $\mathrm{ZnO}$ nanoparticles accumulated in larger amounts than ${ }^{65} \mathrm{ZnNO}_{3}$ in the liver, spleen, and lungs, demonstrating different tissue distributions between ${ }^{65} \mathrm{ZnO}$ particles and ${ }^{65} \mathrm{ZnNO}_{3}{ }^{30}$

Intraperitoneally injected $\mathrm{ZnO}$ nanoparticles $(93 \mathrm{~nm})$ were more effectively distributed in the liver, spleen, kidneys, lungs, and heart in mice, compared to their distribution in the liver, spleen, and kidneys following oral administration. ${ }^{34}$ Meanwhile, inhalation of $20 \mathrm{~nm} \mathrm{ZnO}$ nanoparticles in rats led to elevated zinc content in liver, but severe toxicological effects were observed in both liver and lung tissues. ${ }^{9}$ The liver and kidneys are likely to be common target organs, regardless of different exposure routes, experimental animal types, and physicochemical properties of $\mathrm{ZnO}$ nanoparticles. Therefore, the potential toxicity of $\mathrm{ZnO}$ nanoparticles to these organs has to be considered. Furthermore, the tissue distribution of $\mathrm{ZnO}$ nanoparticles differs from that of zinc ions, which leads us to conclude major particulate uptake into organs.

\section{Excretion}

The excretion kinetics of nanoparticles is important in the context of understanding the elimination processes of wastes or metabolites. In general, entities of less than $6 \mathrm{~nm}$ in hydrodynamic diameter (HD) are capable of glomerular filtration, while those of larger than $8 \mathrm{~nm} \mathrm{HD}$ are not. ${ }^{36,37}$ The renal filtration threshold for proteins is typically less than $5 \mathrm{~nm}$ in HD. ${ }^{38}$ Indeed, nanoparticles with an HD smaller than $5.5 \mathrm{~nm}$ were determined to undergo urinary excretion efficiently. ${ }^{39}$ Therefore, large particles should be decomposed or biodegradable prior to clearance via urine. Conversely, fecal excretion involves the elimination of both nonabsorbed entities after oral ingestion and metabolites excreted via bile that are not reabsorbed from the small intestinal gut.

The excretion kinetics of $\mathrm{ZnO}$ nanoparticles can be affected by exposure routes or physicochemical properties. However, fecal and biliary excretion routes seem to play major roles in nanoparticle elimination, regardless of exposure routes, particle size, surface charge, sex, or experimental animal type. Most orally administered $\mathrm{ZnO}$ nanoparticles ( 20 or $70 \mathrm{~nm}$, negative or positive charge) were excreted via the fecal route in rats, while a small portion of nanoparticles was cleared via urine. ${ }^{25,26}$ Size-dependent urinary excretion kinetics was also demonstrated; $20 \mathrm{~nm}$ nanoparticles were more rapidly cleared compared to $70 \mathrm{~nm}$ nanoparticles, probably associated with easy decomposition or dissolution characteristics of smaller particles. The excretion profile of $\mathrm{ZnO}$ nanoparticles was not dependent on surface charge. ${ }^{26}$ Therefore, particle size rather than surface charge determines the excretion kinetics of nanoparticles. Although no significant effect of particle size on absorption has been found, it is probable that larger $70 \mathrm{~nm}$ particles exhibit more toxicity than $20 \mathrm{~nm}$ ones, because $70 \mathrm{~nm}$ is cleared more slowly than $20 \mathrm{~nm}$. Highly elevated zinc concentration was detected in feces after 13 weeks of consecutive oral administration to rats, ${ }^{21}$ which is in good agreement with the results by Baek et $\mathrm{al}^{25}$ and Paek et al. ${ }^{26}$ Fecal excretion of radioactive $\mathrm{ZnO}$ nanoparticles in mice following intravenous injection was also clearly demonstrated.$^{35}$ It is worth noting that the principal pathway of zinc excretion is via feces, and absorbed zinc is reexcreted into the small intestine via the biliary route, ${ }^{40}$ whereas, zinc elimination through the kidney plays a minor role. ${ }^{40}$ Therefore, the excretion process of $\mathrm{ZnO}$ nanoparticles appears to follow the same pathway as zinc ions.

\section{Biological fate}

Recent studies have focused extensively on the determination of in vivo fates of $\mathrm{ZnO}$ nanoparticles to investigate whether their fates are as intact particulate forms or dissolved ionic forms in cells or tissues. In particular, the solubility of $\mathrm{ZnO}$ nanoparticles must be considered for oral evaluation, because of their high dissolution in acidic fluids versus alkali fluids. ${ }^{15,16,19}$ The biological fates of nanoparticles are still unclear; however, many studies suggest that the primary bioavailable form of $\mathrm{ZnO}$ nanoparticles in tissues is ionic zinc rather than the particulate form.

Cho et al reported complete $40 \mathrm{~nm} \mathrm{ZnO}$ nanoparticle dissolution in simulated gastric fluid compared to almostintact particles in distilled water. ${ }^{21}$ The conclusion was drawn that the absorption of zinc ions from $\mathrm{ZnO}$ nanoparticles under acidic gastric conditions contributes to their oral toxicity - pancreatitis. ${ }^{27}$ Paek et al recently demonstrated a contradicting report of partial dissolution (13\%-14\%) of 20 and $70 \mathrm{~nm} \mathrm{ZnO} \mathrm{nanoparticles} \mathrm{capped} \mathrm{with} \mathrm{citrate/HEPES} \mathrm{or}$ L-serine/HEPES in simulated gastric fluid. ${ }^{26}$ When absorbed plasma levels and tissue-distribution concentration of $\mathrm{ZnO}$ nanoparticles or $\mathrm{ZnCl}_{2}$ were calculated based on soluble 
zinc dose, the difference in kinetics between particles and $\mathrm{ZnCl}_{2}$ was greater, indicating the effect of particulate forms on biokinetic behaviors. ${ }^{26}$ The conflicting results regarding the solubility between two studies may be related to the use of capping agents in the Paek et al study. They also determined that the major fate of $\mathrm{ZnO}$ nanoparticles in tissues was as the ionic form, based on the fact that no particulate forms were observed in transmission electron microscopy on the liver and kidneys following both oral and intravenous administration. ${ }^{26}$

The ionic zinc fate in tissues was also supported by $\mathrm{X}$-ray absorption spectroscopy, showing new $\mathrm{Zn}-\mathrm{S}$ bond formation in organs in rats administered $\mathrm{ZnO}$ nanoparticles; ${ }^{25}$ indeed, $\mathrm{Zn}-\mathrm{O}$ and $\mathrm{Zn}-\mathrm{Zn}$ bonds in the wurtzite structure were found in the reference $\mathrm{ZnO}$ nanoparticles. ${ }^{25}$ Therefore, the nanoparticles enter the blood circulation in both particulate and ionic forms, but mainly as particles, and localize in organs primarily as zinc ions. Finally, the zinc appears to be cleared in the same manner as zinc ions. Li et al suggested that both dissolved zinc ions and nanoparticulate forms must be considered for toxicity evaluation of $\mathrm{ZnO}$ nanoparticles. ${ }^{22}$ Hao et al also identified the toxicity of $\mathrm{ZnO}$ nanoparticles as a function of particle toxicity, and not as a result of only particle dissolution..$^{23}$ Therefore, the question as to whether $\mathrm{ZnO}$ nanoparticles are absorbed into the bloodstream as both particles and zinc ions or only as ionic forms remains to be answered, which may depend on the preparation method or dispersing agent used for nanoparticles.

The fates of $\mathrm{ZnO}$ nanoparticles in human bronchial epithelial cells (BEAS-2B) were determined by scanning transmission $\mathrm{X}$-ray microscopy and $\mathrm{X}$-ray absorption near-edge structure analysis ${ }^{41}$ the nanoparticles are taken up by cells in particulate forms, then completely and rapidly dissolve inside cells, generating $\mathrm{Zn}^{2+}$ ligated by thiol groups. This is consistent with the in vivo $\mathrm{ZnO}$ nanoparticle fate determined by Paek et al. ${ }^{26}$ The bioavailability fate of isotope-labeled $\mathrm{ZnO}$ nanoparticles was traced by coherent anti-Stokes Raman scattering and scanning transmission electron microscopy with energy dispersive X-ray spectroscopy in mud shrimp (Corophium volutator); ${ }^{42}$ ionic zinc from particles in an aqueous environment was determined primarily to contribute to the uptake and bioavailability fate of $\mathrm{ZnO}$ nanoparticles. Although the particulate form affects the kinetics and toxicity of $\mathrm{ZnO}$ nanoparticles, it appears that the fate of $\mathrm{ZnO}$ nanoparticles in tissues or cells is primarily as ionic zinc, which should be considered in underlying the mechanisms of their in vitro and in vivo toxicity (Table 1 and Figure 3). On the other hand, the particle-dissolution properties and ionic fate

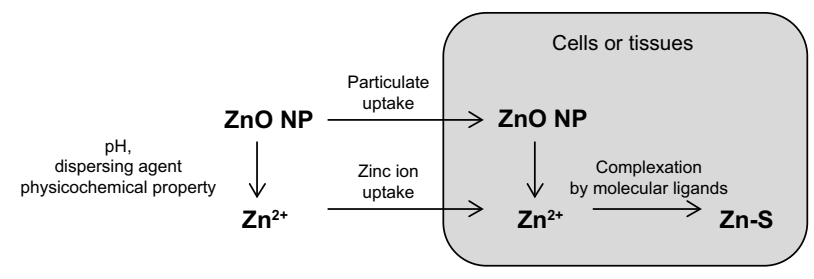

Figure 3 Putative biological fates of zinc oxide $(\mathrm{ZnO})$ nanoparticles (NPs) in cells or tissues.

Notes: $\mathrm{ZnO}$ nanoparticles are dissolved in biological fluids, a process that is highly dependent on the $\mathrm{pH}$ environment and particle size and surface characteristics of nanoparticles, and the presence of other organic compounds or dispersing agents. After being taken up by cells or tissues as particulate and/or ionic forms, nanoparticles are further dissolved, and zinc ions are then complexed by organic ligands, eg, generating $\mathrm{Zn}^{2+}$ ligated by thiol group.

of $\mathrm{ZnO}$ nanoparticles in tissues are not advantageous for such biological applications as drug-delivery systems, diagnostics, and therapeutics, which could be overcome, for example, by using capping agents or coating materials. It is worth noting that part of $\mathrm{ZnO}$ nanoparticles are dissolved in biological fluids, but the nanoparticles retain their particulate forms in the systemic circulation. Therefore, both particulate and zinc ionic fates must be considered to understand the toxicity and TK of $\mathrm{ZnO}$ nanoparticles.

\section{Nanoparticle-protein interaction}

Understanding protein-nanoparticle interaction, so-called nanoparticle-protein corona, is important for the interpretation of biokinetic behaviors, bioavailability, and toxicity potential. When an inorganic or organic material comes in contact with biological fluids, such as blood, rapid interactions occur instantly and lead to protein adsorption on the surface of nanoparticles. Therefore, the interaction of nanoparticles with proteins is highly dependent on the surface characteristics and particle size of the nanoparticles. ${ }^{43,44}$

Most of the studies on nanoparticle-protein interaction have been performed with blood or plasma proteins, such as albumins, immunoglobulins, fibrinogen, lipoproteins, and coagulation factors, to examine binding, adsorption, and changes in protein structure. ${ }^{45-47}$ These types of interactions may cause undesirable toxic effects or facilitate the delivery of nanoparticles to organs, because plasma proteins play a critical role in the disposition, transportation, and deposition of both endogenous and exogenous molecules by noncovalent interaction. ${ }^{48}$ In particular, nanoparticleprotein corona implicates cellular interaction in terms of toxicity, uptake, and immune response. For example, it was reported that albumin-adsorbed single-walled carbon nanotubes contributed to the induction of anti-inflammatory 
response in mouse leukemic monocyte macrophage cell line. ${ }^{49}$ Similarly, adsorption of the pulmonary surfactant protein A on magnetite nanoparticles was determined to enhance cellular binding and uptake of nanoparticles by alveolar macrophages, while albumin adsorption led to a remarkable decrease.$^{50}$ On the other hand, albumin-coated polystyrene nanoparticles were internalized into cells via caveolae-mediated endocytosis, because caveolae are capable of the transcytosis of albumin through the cell membrane. ${ }^{51}$

Apolipoproteins are of importance in the context of their ability to bind to diverse types of nanoparticle surfaces. ${ }^{52}$ In particular, apolipoprotein $\mathrm{E}$ was able to transport nanoparticles across the blood-brain barrier, although a small amount of protein was bound to the surface. ${ }^{53}$ In this case, the neurotoxicity of nanoparticles must be also considered, although apolipoprotein E-adsorbed nanoparticles can be used as carriers for delivering drugs at brain target sites. It is clear that biological activity and molecular targeting of nanoparticles could be dependent on protein types adsorbed on nanoparticles. Furthermore, information about protein structural or conformational changes as a consequence of protein-nanoparticle interaction is crucial, as these may cause a loss of bioactivity and subsequently lead to potential toxicological effects (Figure 4).

Several reports have demonstrated $\mathrm{ZnO}$ nanoparticleprotein interaction. Bovine serum albumin (BSA), the most abundant plasma protein in cows, was adsorbed onto colloidal
$\mathrm{ZnO}$ nanoparticles $(65 \mathrm{~nm})$, and the driving force for this interaction was determined to be electrostatic attraction. ${ }^{54}$ Bhogale et al reported the spontaneous formation of a BSA$\mathrm{ZnO}(7.5 \mathrm{~nm})$ complex by hydrogen and van der Waals forces, resulting in slight conformational modifications in BSA structure ${ }^{46}$ The binding of $\mathrm{ZnO}$ nanoparticles to albumin as well as other plasma proteins, such as protamine and thrombin, was also demonstrated by Gann et al; $;{ }^{55}$ when they also incubated the nanoparticles with human cells, the particles induced a "rounded up" morphology of the cells, which seems to be related to high toxicity. Moreover, $\mathrm{ZnO}$ nanoparticles were determined to be more highly agglomerated in biological buffer containing plasma proteins than in water, leading to an increase in protein binding to the nanoparticles. ${ }^{48}$ When the mechanism of fibrinogen adsorption on $\mathrm{ZnO}$ nanoparticles was investigated, both electrostatic and hydrophobic interactions were responsible for the adsorption, resulting in protein denaturation. ${ }^{56}$ High fibrinogen adsorption was caused by $\mathrm{ZnO}$ nanoparticles with smaller aggregate size versus larger aggregate size; this can be explained by an inverse relationship between aggregate size and surface area. Cytochrome c, an essential protein component of the electron-transport chain, was also used to evaluate its interaction with $60 \mathrm{~nm} \mathrm{ZnO}$ nanoparticles ${ }^{57}$ the structure and thermodynamic stability of cytochrome $\mathrm{c}$ was not significantly affected by its adsorption on the nanoparticles. $\mathrm{ZnO}$ nanoparticles actively interact with biological matrices; however, their interaction affecting

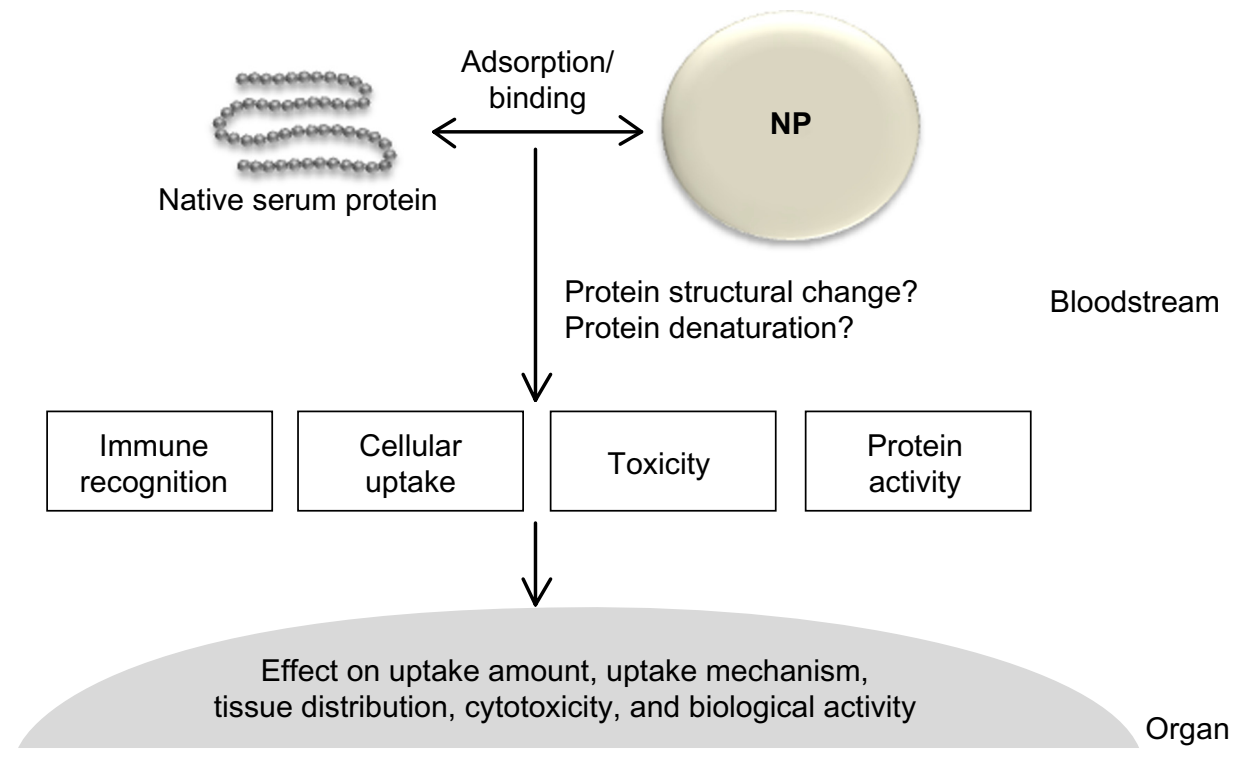

Figure 4 Schematic illustration of nanoparticle-serum protein interaction and possible consequences.

Notes: Serum protein adsorbed on (or bound to) the surface of nanoparticles (NPs) may facilitate immune recognition (uptake and elimination by immune cells) or cellular uptake. Protein conformational changes as a consequence of nanoparticle-protein interaction could cause undesirable toxicological effects or decrease biological activity. Uptake amount, uptake mechanism, and target-organ distribution of nanoparticles can also be influenced by nanoparticle-protein corona. 
biokinetics, absorption, distribution, and toxicity in vivo remains to be elucidated.

\section{Conclusion}

Biokinetic studies on $\mathrm{ZnO}$ nanoparticles are necessary to provide basic information about their absorption characteristics, bioavailability, $\mathrm{t}_{1 / 2}$, residence times, clearance rates, and organs targeted. In particular, such studies are essential in terms of predicting potential toxicological effects and for identifying correlations with acute or subacute toxicity. Although kinetic studies are in their infancy compared with the extensive studies conducted on $\mathrm{ZnO}$ nanoparticle toxicities in vitro and in vivo, recent research on their plasma concentration-time profiles showed different biokinetic profiles of the particles compared to those of zinc ions. Furthermore, their TK persistence at high doses after repeated exposure seems to cause adverse effects. The liver and kidneys were found to be common target organs, regardless of exposure routes, animals tested, and physicochemical properties of nanoparticles. It was also suggested that fecal excretion plays a major role in the clearance of $\mathrm{ZnO}$ nanoparticles. On the other hand, the biological fate of $\mathrm{ZnO}$ nanoparticles is likely to be primarily in the ionic form, not the particulate form, in cells and tissues. However, the question of $\mathrm{ZnO}$ nanoparticle absorption into the circulatory system as particles and/or zinc ions remains to be answered. $\mathrm{ZnO}$ nanoparticles interact with proteins, such as plasma and blood proteins, probably by electrostatic attraction, which leads to protein binding or adsorption. Further in vivo research is essentially required to understand the effects of nanoparticle-protein interaction on biokinetics, absorption, tissue distribution, bioavailability, and potential toxicity.

\section{Acknowledgments}

This research was supported by a grant (10182MFDS991) from the Ministry of Food and Drug Safety in 2012, and partly by Basic Science Research Program through the National Research Foundation of Korea (NRF) funded by the Ministry of Education, Science and Technology (2013R1A1A3009283).

\section{Disclosure}

The authors report no conflicts of interest in this work.

\section{References}

1. Djurisić AB, Leung YH. Optical properties of ZnO nanostructures. Small. 2006;2(8-9):944-961.

2. De Berardis B, Civitelli G, Condello M, et al. Exposure to ZnO nanoparticles induces oxidative stress and cytotoxicity in human colon carcinoma cells. Toxicol Appl Pharmacol. 2010;246(3):116-127.
3. Fan Z, Lu JG. Zinc oxide nanostructures: synthesis and properties. J Nanosci Nanotechnol. 2005;5(10):1561-1573.

4. Kumari L, Li WZ. Synthesis, structure and optical properties of zinc oxide hexagonal microprisms. Cryst Res Technol. 2010;45(3): 311-315.

5. Pasupuleti S, Alapati S, Ganapathy S, Anumolu G, Pully NR, Prakhya BM. Toxicity of zinc oxide nanoparticles through oral route. Toxicol Ind Health. 2012;28(8):675-686.

6. Wang B, Feng W, Wang M, et al. Acute toxicological impact of nano- and submicro-scaled zinc oxide powder on healthy adult mice. J Nanopart Res. 2008;10(2):263-276.

7. Wang B, Feng WY, Wang TC, et al. Acute toxicity of nano- and microscale zinc powder in healthy adult mice. Toxicol Lett. 2006;161(2): $115-123$.

8. Surekha P, Kishore AS, Srinivas A, et al. Repeated dose dermal toxicity study of nano zinc oxide with Sprague-Dawley rats. Cutan Ocul Toxicol. 2012;31(1):26-32.

9. Wang L, Wang L, Ding W, Zhang F. Acute toxicity of ferric oxide and zinc oxide nanoparticles in rats. J Nanosci Nanotechnol. 2010;10(12): 8617-8624.

10. Gao L, Yang ST, Li S, Meng Y, Wang H, Lei H. Acute toxicity of zinc oxide nanoparticles to the rat olfactory system after intranasal instillation. J Appl Toxicol. 2013;33(10):1079-1088.

11. Li SD, Huang L. Pharmacokinetics and biodistribution of nanoparticles. Mol Pharm. 2008;5(4):496-504.

12. Hagens WI, Oomen AG, de Jong WH, Cassee FR, Sips AJ. What do we (need to) know about the kinetic properties of nanoparticles in the body? Regul Toxicol Pharm. 2007;49(3):217-229.

13. Welling PG. Differences between pharmacokinetics and toxicokinetics. Toxicol Pathol. 1995;23(2):143-147.

14. Choi SJ, Choy JH. Effect of physico-chemical parameters on the toxicity of inorganic nanoparticles. J Mater Chem. 2011;21:5547-5554.

15. Li M, Lin D, Zhu L. Effects of water chemistry on the dissolution of $\mathrm{ZnO}$ nanoparticles and their toxicity to Escherichia coli. Environ Pollut. 2013;173:97-102.

16. Mudunkotuwa IA, Rupasinghe T, Wu CM, Grassian VH. Dissolution of $\mathrm{ZnO}$ nanoparticles at circumneutral $\mathrm{pH}$ : a study of size effects in the presence and absence of citric acid. Langmuir. 2012;28(1): 396-403.

17. Cho WS, Duffin R, Howie SE, et al. Progressive severe lung injury by zinc oxide nanoparticles; the role of $\mathrm{Zn}^{2+}$ dissolution inside lysosomes. Part Fibre Toxicol. 2011;8:27.

18. Song W, Zhang J, Guo J, et al. Role of the dissolved zinc ion and reactive oxygen species in cytotoxicity of $\mathrm{ZnO}$ nanoparticles. Toxicol Lett. 2010;199(3):389-397.

19. Henderson LM, Brewer GJ, Dressman JB, et al. Effect of intragastric pH on the absorption of oral zinc acetate and zinc oxide in young healthy volunteers. JPEN J Parenter Enteral Nutr. 1995;19(5):393-397.

20. Miao AJ, Zhang XY, Luo Z, et al. Zinc oxide-engineered nanoparticles: dissolution and toxicity to marine phytoplankton. Environ Toxicol Chem. 2010;29(12):2814-2822.

21. Cho WS, Kang BC, Lee JK, Jeong J, Che JH, Seok SH. Comparative absorption, distribution, and excretion of titanium dioxide and zinc oxide nanoparticles after repeated oral administration. Part Fibre Toxicol. 2013;10:9.

22. Li WM, Wang WX. Distinct biokinetic behavior of $\mathrm{ZnO}$ nanoparticles in Daphnia magna quantified by synthesizing ${ }^{65} \mathrm{Zn}$ tracer. Water Res. 2013;47(2):895-902.

23. Hao L, Chen L, Hao J, Zhong N. Bioaccumulation and sub-acute toxicity of zinc oxide nanoparticles in juvenile carp (Cyprinus carpio): a comparative study with its bulk counterparts. Ecotoxicol Environ Saf. 2013;91:52-60.

24. Riviere JE. Pharmacokinetics of nanomaterials: an overview of carbon nanotubes, fullerenes and quantum dots. Wiley Interdiscip Rev Nanomed Nanobiotechnol. 2009;1(1):26-34.

25. Baek M, Chung HE, Yu J, et al. Pharmacokinetics, tissue distribution, and excretion of zinc oxide nanoparticles. Int J Nanomedicine. 2012;7:3081-3097. 
26. Paek HJ, Lee YJ, Chung HE, et al. Modulation of the pharmacokinetics of zinc oxide nanoparticles and their fates in vivo. Nanoscale. 2013; 5(23):11416-11427.

27. Seok SH, Cho WS, Park JS, et al. Rat pancreatitis produced by 13 -week administration of zinc oxide nanoparticles: biopersistence of nanoparticles and possible solutions. J Appl Toxicol. 2013;33(10):1089-1096.

28. Chung HE, Yu J, Baek M, et al. Toxicokinetics of zinc oxide nanoparticles in rats. J Phys Conf Ser. 2013;429:012037.

29. National Institutes of Health. Zinc Fact Sheet for Health Professionals [webpage on the Internet]. Available from: http://ods.od.nih.gov/ factsheets/Zinc-HealthProfessional. Accessed May 5, 2014.

30. Yeh TK, Chen JK, Lin CH, et al. Kinetics and tissue distribution of neutron-activated zinc oxide nanoparticles and zinc nitrate in mice: effects of size and particulate nature. Nanotechnology. 2012;23(8):085102.

31. Souris JS, Lee CH, Cheng SH, et al. Surface charge-mediated rapid hepatobiliary excretion of mesoporous silica nanoparticles. Biomaterials. 2010;31(21):5564-5574.

32. Lee CM, Jeong HJ, Yun KN, et al. Optical imaging to trace near infrared fluorescent zinc oxide nanoparticles following oral exposure. Int $J$ Nanomedicine. 2012;7:3203-3209.

33. Lee CM, Jeong HJ, Kim DW, Sohn MH, Lim ST. The effect of fluorination of zinc oxide nanoparticles on evaluation of their biodistribution after oral administration. Nanotechnology. 2012;23(20):205102-205108.

34. Li CH, Shen CC, Cheng YW, et al. Organ biodistribution, clearance, and genotoxicity of orally administered zinc oxide nanoparticles in mice. Nanotoxicology. 2012;6(7):746-756.

35. Chen JK, Shih MH, Peir JJ, et al. The use of radioactive zinc oxide nanoparticles in determination of their tissue concentrations following intravenous administration in mice. Analyst. 2010;135(7):1742-1746.

36. Deen WM, Lazzara MJ, Myers BD. Structural determinants of glomerular permeability. Am J Physiol Renal Physiol. 2001;281(4):F579-F596.

37. Longmire M, Choyke PL, Kobayashi H. Clearance properties of nanosized particles and molecules as imaging agents: considerations and caveats. Nanomedicine (Lond). 2008;3(5):703-717.

38. Ohlson M, Sörensson J, Haraldsson B. A gel-membrane model of glomerular charge and size selectivity in series. Am J Physiol Renal Physiol. 2001;280(3):F396-F405.

39. Choi HS, Liu W, Misra P, et al. Renal clearance of quantum dots. Nat Biotechnol. 2007;25(10):1165-1170.

40. Hambidge M, Krebs NF. Interrelationships of key variables of human zinc homeostasis: relevance to dietary zinc requirements. Annu Rev Nutr. 2001;21:429-452.

41. Gilbert B, Fakra SC, Xia T, Pokhrel S, Mädler L, Nel AE. The fate of $\mathrm{ZnO}$ nanoparticles administered to human bronchial epithelial cells. ACS Nano. 2012;6(6):4921-4930.

42. Larner F, Dogra Y, Dybowska A, et al. Tracing bioavailability of ZnO nanoparticles using stable isotope labeling. Environ Sci Technol. 2012;46(21):12137-12145.
43. Mieszawska AJ, Jalilian R, Sumanasekera GU, Zamborini FP. The synthesis and fabrication of one-dimensional nanoscale heterojunctions. Small. 2007;3(5):722-756.

44. Lu MY, Song J, Lu MP, Lee CY, Chen LJ, Wang ZL. ZnO-ZnS heterojunction and $\mathrm{ZnS}$ nanowire arrays for electricity generation. ACS Nano. 2009;3(2):357-362.

45. Zhang YZ, Zhou B, Liu YX, Zhou CX, Ding XL, Liu Y. Fluorescence study on the interaction of bovine serum albumin with p-aminoazobenzene. J Fluoresc. 2008;18(1):109-118.

46. Bhogale A, Patel N, Sarpotdar P, et al. Systematic investigation on the interaction of bovine serum albumin with $\mathrm{ZnO}$ nanoparticles using fluorescence spectroscopy. Colloids Surf B Biointerfaces. 2013;102: 257-264.

47. Xiao J, Wang F, Liu J, Wang L, Kai G, Yu X. Effect of ZnO\#ZnS QDs heterojunctures on the stilbenes-plasma proteins interactions. $\mathrm{Mol}$ Biosyst. 2011;7(8):2452-2458.

48. Deng ZJ, Mortimer G, Schiller T, Musumeci A, Martin D, Minchin RF. Differential plasma protein binding to metal oxide nanoparticles. Nanotechnology. 2009;20(45):455101.

49. Dutta D, Sundaram S, Teeguarden J, et al. Adsorbed proteins influence the biological activity and molecular targeting of nanomaterials. Toxicol Sci. 2007;100(1):303-315.

50. Ruge CA, Kirch J, Cañadas O, et al. Uptake of nanoparticles by alveolar macrophage is triggered by surfactant protein A. Nanomedicine. 2011;7(6):690-693.

51. Wang Z, Tiruppathi C, Minshall RD, Malik AB. Size and dynamics of caveolae studied using nanoparticles in living endothelial cells. ACS Nano. 2009;3(12):4110-4116.

52. Saptarshi SR, Duschl Al, Lopata AL. Interaction of nanoparticles with proteins: relation to bio-activity of the nanoparticles. J Nanobiotechnol. 2013;11:26.

53. Kreuter J, Shamenkov D, Petrov V, et al. Apolipoprotein-mediated transport of nanoparticle-bound drugs across the blood-brain barrier. J Drug Target. 2002;10(4):317-325.

54. Sasidharan NP, Chandran P, Sudheer Khan S. Interaction of colloidal zinc oxide nanoparticles with bovine serum albumin and its adsorption isotherms and kinetics. Colloids Surf B Biointerfaces. 2013;102: 195-201.

55. Gann H, Glaspell G, Garrad R, et al. Interaction of $\mathrm{MnO}$ and $\mathrm{ZnO}$ nanomaterials with biomedically important proteins and cells. J Biomed Nanotechnol. 2010;6(1):37-42.

56. Lousinian S, Missopolinou D, Panayiotou C. Fibrinogen adsorption on zinc oxide nanoparticles: a micro-differential scanning calorimetry analysis. J Colloid Interface Sci. 2013;395:294-299.

57. Šimšíková M, Antalík M. Interaction of cytochrome c with zinc oxide nanoparticles. Colloids Surf B Biointerfaces. 2013;103:630-634.
International Journal of Nanomedicine

\section{Publish your work in this journal}

The International Journal of Nanomedicine is an international, peerreviewed journal focusing on the application of nanotechnology in diagnostics, therapeutics, and drug delivery systems throughout the biomedical field. This journal is indexed on PubMed Central,

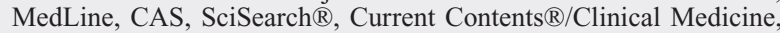

\section{Dovepress}

Journal Citation Reports/Science Edition, EMBase, Scopus and the Elsevier Bibliographic databases. The manuscript management system is completely online and includes a very quick and fair peer-review system, which is all easy to use. Visit http://www.dovepress.com/ testimonials.php to read real quotes from published authors. 